\title{
Administration of Saccharomyces boulardii mafic-1701 improves feed conversion ratio, promotes antioxidant capacity, alleviates intestinal inflammation and modulates gut microbiota in weaned piglets
}

\author{
Wenxiu Zhang, Chengling Bao, Jian Wang, Jianjun Zang and Yunhe Cao* (i)
}

\begin{abstract}
Background: Probiotics are used as a means to improve animal health and intestinal development. Saccharomyces boulardii is a well-known probiotic; however, few studies have examined the effects of S. boulardii on weaned piglet performance. Therefore, this 28-day study compared the effects of S. boulardii mafic-1701 and aureomycin in diets for weaned piglets on growth performance, antioxidant parameters, inflammation and intestinal microbiota. One hundred and eight piglets, weaned at $28 \mathrm{~d}$ of age $(8.5 \pm 1.1 \mathrm{~kg})$, were randomly divided into the three dietary treatment groups with six pens and six piglets per pen (half male and half female). The dietary treatment groups were as follows: 1) basal diet (CON); 2) basal diet supplemented with $75 \mathrm{mg} / \mathrm{kg}$ aureomycin (ANT); 3) basal diet supplemented with $1 \times 10^{8} \mathrm{CFU} / \mathrm{kg}$ S. boulardii mafic-1701 (SB).
\end{abstract}

Results: Compared to CON group, SB group had higher feed efficiency $(P<0.05)$ in the last $14 \mathrm{~d}$ and lower diarrhea rate $(P<0.05)$ over the entire $28 \mathrm{~d}$. Total superoxide dismutase in serum was markedly increased in SB group $(P<$ 0.05). Moreover, compared with CON group, SB group decreased the levels of pro-inflammatory cytokines interleukin-6 $(P<0.01)$ and Tumor necrosis factor-a $(P<0.05)$ in jejunum. Supplementation of S. boulardii mafic1701 increased the abundance of Ruminococcaceae_UCG_009 and Turicibacter $(P<0.05)$, whereas the abundance of unclassified_Clostridiaceae_4 was decreased $(P<0.05)$. Furthermore, S. boulardii mafic-1701 administration increased cecal concentration of microbial metabolites, isobutyrate and valerate $(P<0.05)$.

Conclusions: The improvement in feed conversion ratio, reduction in diarrhea rate in weaned piglets provided diets supplemented with S. boulardii mafic-1701 may be associated with enhanced antioxidant activity, antiinflammatory responses and improved intestinal microbial ecology.

Keywords: Inflammation, Microbiota, Saccharomyces boulardii, Short chain fatty acid, Weaned piglet

\footnotetext{
* Correspondence: Caoyh@cau.edu.cn

State Key Laboratory of Animal Nutrition, College of Animal Science and

Technology, China Agricultural University, Beijing 100193, China
}

C C The Author(s). 2020 Open Access This article is licensed under a Creative Commons Attribution 4.0 International License, which permits use, sharing, adaptation, distribution and reproduction in any medium or format, as long as you give appropriate credit to the original author(s) and the source, provide a link to the Creative Commons licence, and indicate if changes were made. The images or other third party material in this article are included in the article's Creative Commons licence, unless indicated otherwise in a credit line to the material. If material is not included in the article's Creative Commons licence and your intended use is not permitted by statutory regulation or exceeds the permitted use, you will need to obtain permission directly from the copyright holder. To view a copy of this licence, visit http://creativecommons.org/licenses/by/4.0/. The Creative Commons Public Domain Dedication waiver (http://creativecommons.org/publicdomain/zero/1.0/) applies to the data made available in this article, unless otherwise stated in a credit line to the data. 


\section{Background}

In order to market pigs sooner and to improve sows' reproductive performance, the early weaning strategy has been applied in commercial pig production [1]. Weaning is the most stressful period in pig's life [1]. Some nonantibiotic solutions, including antimicrobial peptides, prebiotics, anti-virulence molecules, antibodies and probiotics, have been developed to maintain the health status of newly weaned piglets [2-4].

Probiotics are defined as "friendly" live microorganisms. When administered in adequate amounts, probiotics can confer a health benefit to the host [5]. Saccharomyces boulardii is a safe, efficacious and non-pathogenic yeast isolated from lychee fruit in Indochina; $S$. boulardii belongs to Saccharomyces cerevisiae species [6]. However, $S$. boulardii possesses a superior probiotic efficiency than other stains of Saccharomyces cerevisiae by exhibiting several distinct physiological and metabolic characteristics [6]. In particular, characteristics of S. boulardii that make it suitable for use in weaned piglet diets include heat tolerance and resistance to gastric acidity, bile and proteolysis $[7,8]$. The degree of acid tolerance and resistance to enzyme digestion suggest that $S$. boulardii may be suited for survival in the intestines. In addition, accumulating evidence suggests oral administration $S$. boulardii may protect animals against antibiotic-associated diarrhea and Clostridium difficile-associated colitis in animal models [9, 10]. In human studies, administration of $S$. boulardii protected humans against Clostridium difficile infection, mitigated intestinal microbiota disorder and reduced antibiotic-associated diarrhea $[11,12]$.

The beneficial properties mentioned here indicate that $S$. boulardii would be used as a promising probioticbased feed additive in animal production. However, the effects of $S$. boulardii on weaned piglets remain unclear. Therefore, the objective of this study was to determine whether S. boulardii mafic-1701 supplementation to weaned piglet diets would improve feed conversion ratio, antioxidant capacity in serum, gut anti-inflammatory responses, microbiota composition and fermentation metabolites concentrations in weaned piglets.

\section{Materials and methods}

Experimental protocols of animal handling and dietary treatments were approved by the "Institutional Animal Care and Use Committee of China Agricultural University" (ICS 65.020.30). All animal procedures were carried out in accordance with the specifications of the National Research Council's Guide for the Welfare and Ethics of Laboratory Animals.

\section{Probiotic strain and culture conditions}

The yeast $S$. boulardii mafic-1701 was isolated by our laboratory and maintained on yeast extract peptone dextrose agar plates to screen single colonies. Colonies of S. boulardi mafic-1701 were inoculated in yeast extract peptone dextrose medium for $16 \mathrm{~h}$ at $37^{\circ} \mathrm{C}$ to prepare seed cultures. High density fermentation cultivation was performed using a fermentor $(30 \mathrm{~L})$ with an initial volume of $15 \mathrm{~L}$ of medium with the following composition $(\mathrm{g} / \mathrm{L})$ : dextrose, 50; corn steep liquor powder, 25; $\left(\mathrm{NH}_{4}\right)_{2} \mathrm{SO}_{4}, 4 ; \mathrm{KH}_{2} \mathrm{PO}_{4}, 2 ; \mathrm{MgSO}_{4}, 0.5 .750 \mathrm{~mL}$ of seed cultures were added into medium. The initial dissolved oxygen concentration was adjusted to $30 \%$. The $\mathrm{pH}$ was set at 6.5 using $3 \mathrm{~mol} / \mathrm{L} \mathrm{NaOH}$. Fermentation was processed at $37^{\circ} \mathrm{C}$ at $250 \mathrm{r} / \mathrm{min}$ with an aeration rate of $5 \mathrm{~L} /$ min of air. The $\mathrm{pH}$ was maintained at 6.5 by the addition of $3 \mathrm{~mol} / \mathrm{L} \mathrm{NaOH}$ and anti-foaming agents were automatically added when each time foam was generated. Samples were collected every $12 \mathrm{~h}$ to measure the biomass of $S$. boulardii mafic-1701 fermented. The yeast product used in this present study was obtained by mixing the precipitate of the fermentation broth with 21.57 $\mathrm{kg}$ wheat bran [13]. The final product moisture content was controlled at $2 \%$ by drying at the temperature of $37^{\circ} \mathrm{C}$.

\section{Experimental design and diets}

The experiment was conducted at Feng Ning Swine Research Unit of China Agriculture University (Academician Workstation in Chengdejiuyun Agricultural \& Livestock Co., Ltd). The experiment was conducted as a completely randomized design. A total of 108 piglets (Duroc $\times$ Landrace $\times$ Yorkshire) were weaned at $28 \mathrm{~d}$ of age $(8.5 \pm 1.1 \mathrm{~kg})$, and randomly assigned to one of three dietary treatment groups, based on their gender and initial body weight. Treatment diets included basal diet (CON), basal diet supplemented with $75 \mathrm{mg} / \mathrm{kg}$ aureomycin (Chia Tai Group, Henan, China) (ANT) [14] and basal diet supplemented with $1 \times 10^{8} \mathrm{CFU} / \mathrm{kg} \mathrm{S}$. boulardii mafic-1701 (SB). Basal diets (Table 1) in this study were formulated to meet or exceed NRC (2012) nutritional requirements of piglets in 2 phases (d 0-14 and d 15-28) after weaning. Each treatment group consisted of 6 replicate pens and each pen consisted 3 male and 3 female piglets. All piglets were housed in $1.2 \mathrm{~m} \times 2.1 \mathrm{~m}$ pens equipped with plastic leakage dung floors and were allowed ad libitum access to water and feed. Room temperature setpoint was $26^{\circ} \mathrm{C}$ on the day of weaning and gradually decreased to $22^{\circ} \mathrm{C}$ within the first week after weaning. The humidity was held constant at $65-75 \%$.

\section{Performance and diarrhea incidence}

Piglets and feeders were weighted on d 0, 14 and 28. Average daily gain (ADG), average daily feed intake (ADFI) and feed to gain ratio (F:G) were calculated on a pen basis. To evaluate the rate of diarrhea, fecal consistency was visually assessed three times per day 
Table 1 Composition and nutrient levels of basal diets (as-fed basis)

\begin{tabular}{|c|c|c|}
\hline \multirow[b]{2}{*}{ Items $^{a}$} & \multicolumn{2}{|l|}{ Diet } \\
\hline & d 0-14 & d 15-28 \\
\hline \multicolumn{3}{|l|}{ Ingredient, \% } \\
\hline Corn & 59.82 & 64.32 \\
\hline Soybean meal & 15.00 & 15.80 \\
\hline Extruded soybean & 6.30 & 6.00 \\
\hline Fish meal & 4.00 & 3.50 \\
\hline Whey powder & 4.00 & 3.15 \\
\hline Soybean protein concentrate & 4.80 & 2.80 \\
\hline Soybean oil & 2.20 & 0.90 \\
\hline Dicalcium phosphate & 1.15 & 1.00 \\
\hline Limestone & 0.82 & 0.60 \\
\hline Salt & 0.30 & 0.30 \\
\hline L-lysine $\mathrm{HCl}$ & 0.52 & 0.44 \\
\hline Methionine & 0.18 & 0.12 \\
\hline Threonine & 0.18 & 0.14 \\
\hline Serine & 0.03 & 0.03 \\
\hline Chromic oxide & 0.00 & 0.03 \\
\hline Choline chloride & 0.20 & 0.10 \\
\hline Vitamin-mineral premix ${ }^{\mathrm{b}}$ & 0.50 & 0.50 \\
\hline Total & 100.00 & 100.00 \\
\hline \multicolumn{3}{|l|}{ Selected nutrient level, calculated ${ }^{c}$} \\
\hline Digestible energy, Mcal/kg & 3.55 & 3.48 \\
\hline SID ${ }^{d}$ Lysine, $\%$ & 1.39 & 1.25 \\
\hline SID Methionine, \% & 0.49 & 0.41 \\
\hline SID Threonine, \% & 0.96 & 0.74 \\
\hline SID Serine, \% & 0.26 & 0.22 \\
\hline Crude protein, $\%$ & 20.81 & 19.53 \\
\hline Calcium, \% & 0.84 & 0.70 \\
\hline Total phosphorous, $\%$ & 0.65 & 0.61 \\
\hline
\end{tabular}

${ }^{2}$ Experimental diets were control diet (CON), CON $+75 \mathrm{mg} / \mathrm{kg}$ aureomycin (ANT), CON $+1 \times 10^{8} \mathrm{CFU} / \mathrm{kg}$ S. boulardii mafic-1701 (SB)

${ }^{\mathrm{b}}$ The vitamin-mineral premix contained (per kilogram of complete diet): vitamin $\mathrm{A}, 9000 \mathrm{IU}$; vitamin $\mathrm{D}_{3}, 3000 \mathrm{IU}$; vitamin $\mathrm{E}$, $20.0 \mathrm{lU}$; vitamin $\mathrm{K}_{3}, 3.0 \mathrm{mg}$; vitamin $B_{1}, 1.5 \mathrm{mg}$; vitamin $B_{2}, 4.0 \mathrm{mg}$; vitamin $B_{6}, 3.0 \mathrm{mg}$; vitamin $B_{12}, 0.2 \mathrm{mg}$; niacin, $30.0 \mathrm{mg}$; pantothenic acid, $15.0 \mathrm{mg}$; folic acid, $0.75 \mathrm{mg}$; biotin, $0.1 \mathrm{mg}$; $\mathrm{Fe}\left(\mathrm{FeSO}_{4} \cdot \mathrm{H}_{2} \mathrm{O}\right), 75.0 \mathrm{mg} ; \mathrm{Cu}\left(\mathrm{CuSO}_{4} \cdot 5 \mathrm{H}_{2} \mathrm{O}\right), 150 \mathrm{mg} ; \mathrm{Zn}\left(\mathrm{ZnSO}_{4} \cdot 7 \mathrm{H}_{2} \mathrm{O}\right), 90 \mathrm{mg}$; $\mathrm{Mn}\left(\mathrm{MnSO}_{4}\right), 60.0 \mathrm{mg} ; \mathrm{I}(\mathrm{KI}), 0.35 \mathrm{mg} ; \mathrm{Se}\left(\mathrm{Na}_{2} \mathrm{SeO}_{3}\right), 0.30 \mathrm{mg}$

'Values were calculated according to NRC (2012). ${ }^{\mathrm{d}} \mathrm{SID}$ : standardized ileal digestible

throughout the experiment by fixed observers blind to the treatment according to the method described by Hart and Dobb [15]. The scoring system was applied to determine the rate of diarrhea as following: $1=$ normal feces; 2 = possible slight diarrhea; 3 = fluid feces; $4=$ very watery diarrhea [16]. The occurrence of diarrhea was defined as maintaining fecal scores of 3 or 4 for 2 consecutive days [16]. The rate of diarrhea was calculated according to the following formula: the rate of diarrhea
$(\%)=($ number of piglets with diarrhea $\times$ diarrhea days $) /$ (number of piglets $\times$ total observational days) $\times 100$ [16]

\section{Sample collection and processing}

On the $\mathrm{d} 28$, one piglet from each replicate pen close to the median body weight was selected for sampling. Blood $(7 \mathrm{~mL})$ was collected via jugular venipuncture using vacutainer without anticoagulant (Greiner BioOne GmbH, Kremsmunster, Austria) [17], which was subsequently centrifuged at $3000 \times g$ for $15 \mathrm{~min}$ for serum preparation and stored at $-80^{\circ} \mathrm{C}$ until further analysis.

Three piglets per treatment group were randomly selected for slaughter. The selected piglets were from the different pens and their body weights were close to the median body weight [14]. Approximately $10 \mathrm{~g}$ digesta from the mid cecum and colon of each piglet were collected in sterile tubes, flash frozen in liquid nitrogen and stored at $-80^{\circ} \mathrm{C}$ until further analysis [13]. One aliquot of digesta samples were obtained for microbial composition analysis and additional subsamples were taken to determine the short chain fatty acids (SCFAs) in the gut. Intestinal tissues $(3.0 \mathrm{~cm})$ were respectively taken from jejunum and ileum, washed with normal saline to remove gut contents, immediately preserved in liquid nitrogen and kept at $-80^{\circ} \mathrm{C}$ for anti-inflammatory analysis.

\section{Serum immune and antioxidant parameters}

Serum immunoglobulins (IgA and IgG) were analyzed using commercially available ELISA kits following manufacturer's instructions (Nanjing Jiancheng Bioengineering Institute, Nanjing, China). The antioxidant capacity based on serum concentrations of total superoxide dismutase (T-SOD), malondialdehyde (MDA), total antioxidant capacity (T-AOC) and glutathione peroxidase (GSH-Px) were assessed using commercially available ELISA kits according to manufacturer's instructions (Nanjing Jiancheng Bioengineering Institute, Nanjing, China).

\section{Cytokine measurement}

The tissue concentrations of interleukin-8 (IL-8), interleukin-4 (IL-4), interleukin-6 (IL-6) and tumor necrosis factor- $\alpha$ (TNF- $\alpha$ ) were determined with commercially available ELISA kits following the manufacturer's instructions (Nanjing Jiancheng Bioengineering Institute, Nanjing, China). Briefly, samples of the jejunum and ileum tissues were thawed and homogenized in PBS (1:9 $\mathrm{wt} / \mathrm{vol}, \mathrm{pH} 7.4$ ) and centrifuged at $2000 \times g$ for $20 \mathrm{~min}$. The supernatant was collected for the determination.

\section{Microbiota analysis}

Microbial community genomic DNA was isolated from cecal and colonic digesta, using the E.Z.N.A. ${ }^{\circledR}$ stool DNA 
kit (Omega Bio-tek, Norcross, GA, USA) according to the manufacturer's specifications. The V3-V4 regions of the bacterial $16 \mathrm{~S}$ rRNA gene were amplified by PCR using universal primers 338F (5'-ACTCCTACGGGAGG CAGCAG-3') and 806R (5'-GGACTACHVGGG TWTCTAAT-3') with the following procedures: initial denaturation at $95^{\circ} \mathrm{C}$ for $3 \mathrm{~min}$, followed by 27 cycles of denaturing at $95^{\circ} \mathrm{C}$ for $30 \mathrm{~s}$, annealing at $55^{\circ} \mathrm{C}$ for $30 \mathrm{~s}$, extension at $72{ }^{\circ} \mathrm{C}$ for $45 \mathrm{~s}$, single extension at $72{ }^{\circ} \mathrm{C}$ for $10 \mathrm{~min}$ and end at $4{ }^{\circ} \mathrm{C}$ [18]. Illumina sequencing was performed, raw data were quality-filtered using Trimmomatic and merged by FLASH software with the following criteria: 1 ) average quality score less than 20 were truncated. A 50-bp sliding window was set and reads shorter than $50 \mathrm{bp}$ or containing ambiguous reads were discarded; 2) sequences longer than $10 \mathrm{bp}$ were assembled based on their overlapped sequence. The maximum mismatch ratio of overlap area was 0.2 . Unassembled reads were discarded; 3) samples were distinguished according to their barcode and primers, and the reads with ambiguous bases were removed [18].

Using UPARSE (version 7.1, http://drive5.com/uparse/) operational taxonomic units (OTUs) with $97 \%$ similarity cutoff were clustered and chimeric sequences were filtered out. Each 16S rRNA representative gene sequence was categorized and analyzed by RDP Classifier (http://rdp. cme.msu.edu/) against the Silva (SSU128) 16S rRNA database using confidence threshold of 70\% [13].

\section{Quantification of fermentation products}

The concentrations of SCFAs were assayed as literature reported $[4,14]$. Briefly, approximately $0.5 \mathrm{~g}$ of intestinal digesta was weighed into a $10-\mathrm{mL}$ polypropylene tube and diluted 1:16 with ultrapure water $(8 \mathrm{~mL})$. Glass spheres were added and vortexed to homogenize the contents. Polypropylene tubes were paced in an ultrasonic bath (KQ5200DE; Kunshan Ultrasonic Instrument, Jiangsu, China) at room temperature for $30 \mathrm{~min}$. Then, the mixture was centrifuged at $4000 \times g$ for $15 \mathrm{~min}$. Next, $0.16 \mathrm{~mL}$ of supernatant transferred into a $10-\mathrm{mL}$ tube with $7.84 \mathrm{~mL}$ ultrapure water and filtered through a $0.22-\mu \mathrm{m}$ filter. The SCFAs in a $25-\mu \mathrm{L}$ extracted sample solution were determined by high performance ion chromatography (ICS-3000; Dionex, USA) with a conductivity detector. Finally, the concentrations of SCFAs were calculated and normalized to intestinal digesta weight as milligrams per kilogram.

\section{Statistical analysis}

Replicate (pen) was considered the experimental unit for analysis of differences in growth performance and diarrhea rate. Individual piglets were considered the experimental unit for analyses of serum immunoglobulins, antioxidant parameters, gut inflammatory parameters, microbiota, and SCFAs. Growth performance, serum immune, antioxidant parameters, inflammatory parameters and SCFAs were analyzed by one-way ANOVA using Bonferroni test (SPSS Inc., Chicago, IL, USA). Diarrhea rate were analyzed by Chi-square test (SPSS Inc., Chicago, IL, USA) [19, 20]. The bacterial community at the level of phylum, family and genus were analyzed by Kruskal-Wallis method followed by Welch's test [13, 20]. Probability values of $P<0.05$ were considered statistical significance.

\section{Results}

\section{Growth performance and diarrhea incidence}

The effects of dietary treatment on ADFI, ADG and F:G are presented in Table 2. There were no significant differences in ADFI and ADG among three treatment groups $(P>0.05)$. However, compared with $\mathrm{CON}$ group, SB group had lower F:G during d 15 to $28(P<0.05)$ and d 0 to $28(P<0.01)$. The rate of diarrhea was significantly associated with the dietary treatment (Table 3 ). Over the entire $28 \mathrm{~d}, \mathrm{SB}$ group markedly decreased the rate of diarrhea compared to CON group $(P<0.05)$.

\section{Serum immune and antioxidant parameters}

The serum concentration of T-SOD was increased in SB group than that of piglets in CON group $(P<0.05)$ (Table 4). Moreover, the serum concentrations of $\mathrm{T}$ AOC, MDA and GSH-Px did not significantly differ among three treatment groups. There were no

Table 2 Effect of S. boulardii mafic-1701 on growth performance in weaned piglets ${ }^{*}$

\begin{tabular}{|c|c|c|c|c|c|}
\hline Items & CON & ANT & SB & SEM & $P$-value \\
\hline d 0 body weight, kg & 8.4 & 8.6 & 8.5 & 0.26 & 0.97 \\
\hline d 14 body weight, kg & 12.8 & 13.6 & 13.0 & 0.38 & 0.71 \\
\hline d 28 body weight, kg & 20.1 & 22.1 & 21.4 & 0.57 & 0.37 \\
\hline \multicolumn{6}{|l|}{ d 0 to 14} \\
\hline$A D G, g / d$ & 311.6 & 347.4 & 320.1 & 10.58 & 0.38 \\
\hline ADFI, g/d & 488.6 & 527.7 & 476.9 & 16.25 & 0.44 \\
\hline$F: G$ & 1.58 & 1.52 & 1.47 & 0.04 & 0.56 \\
\hline \multicolumn{6}{|l|}{ d 15 to 28} \\
\hline$A D G, g / d$ & 511.0 & 565.2 & 579.1 & 17.52 & 0.28 \\
\hline$A D F I, g / d$ & 1096.4 & 1204.7 & 1112.5 & 33.77 & 0.39 \\
\hline$F: G$ & $2.17^{\mathrm{a}}$ & $2.14^{\mathrm{ab}}$ & $1.92^{b}$ & 0.04 & 0.02 \\
\hline \multicolumn{6}{|l|}{ d 0 to 28} \\
\hline$A D G, g / d$ & 421.7 & 490.0 & 463.3 & 13.99 & 0.31 \\
\hline$A D F I, g / d$ & 810.0 & 873.3 & 810.0 & 22.64 & 0.42 \\
\hline$F: G$ & $1.92^{\mathrm{a}}$ & $1.82^{\mathrm{b}}$ & $1.78^{b}$ & 0.02 & $<0.01$ \\
\hline
\end{tabular}


Table 3 Effect of S. boulardii mafic-1701 on the rate of diarrhea (\%) in weaned piglets ${ }^{*}$

\begin{tabular}{lllll}
\hline Experiment phases & CON & ANT & SB & $P$-value \\
\hline d 0 to 14 & $20.24^{\mathrm{a}}$ & $11.11^{\mathrm{b}}$ & $11.31^{\mathrm{ab}}$ & 0.02 \\
d 15 to 28 & $7.14^{\mathrm{a}}$ & $3.17^{\mathrm{b}}$ & $4.37^{\mathrm{a}}$ & 0.03 \\
d 0 to 28 & $13.69^{\mathrm{a}}$ & $7.14^{\mathrm{b}}$ & $7.84^{\mathrm{b}}$ & $<0.01$
\end{tabular}

${ }^{*} n=6$ per pen, experimental diets were control diet (CON), CON $+75 \mathrm{mg} / \mathrm{kg}$ aureomycin (ANT), CON $+1 \times 10^{8} \mathrm{CFU} / \mathrm{kg} \mathrm{S}$. boulardii mafic-1701 (SB). The rate of diarrhea was calculated according to the following formula: the rate of diarrhea $(\%)=$ (number of piglets with diarrhea $\times$ diarrhea days) $/($ number of piglets $\times$ total observational days) $\times 100$. In the same row, values with different lowercase letter superscripts mean significant difference $(P<0.05)$

significant differences in the serum concentrations of IgA and IgG among three treatment groups (Table 4).

\section{Intestinal inflammatory responses}

The levels of TNF- $\alpha(P<0.01)$ and IL-6 $(P<0.05)$ in jejunum were decreased significantly in ANT group compared to CON group (Table 5). Similarly, SB group markedly decreased the levels of TNF- $\alpha(P<0.05)$ and IL-6 $(P<0.01)$ in jejunum. In addition, no significant differences were observed on the levels of IL-8 and IL-4 among three treatment groups $(P>0.05)$.

\section{Intestinal microbiota composition}

The OTUs were classified for bacterial community on the basis of usable sequence at $97 \%$ similarity. The analysis of OTUs in the cecal and colonic digesta are shown in Fig. 1. There were 42, 66, 268 unique OTUs in the cecal digesta of the CON group, ANT group, and SB group respectively and a total of 325 OTUs were common to all treatment groups. In the colonic digesta, 712 OTUs were common among the three treatment groups with 419, 318, 799 OTUs unique to CON group, ANT group and SB group, respectively. Figure 2 depicts the microbial composition of cecal and colonic digesta across three treatment groups. In the cecal digesta, Firmicutes was the most predominant phylum among the three treatment groups, and Bacteroidetes was the second abundant phylum in ANT group and SB group.

Table 4 Effect of S. boulardii mafic-1701 on serum immune and antioxidant parameters in weaned piglets

\begin{tabular}{llllll}
\hline Items & CON & ANT & SB & SEM & $P$-value \\
\hline $\mathrm{IgA}, \mathrm{g} / \mathrm{L}$ & 1.00 & 1.38 & 1.30 & 0.09 & 0.16 \\
$\mathrm{lgG}, \mathrm{g} / \mathrm{L}$ & 10.01 & 11.24 & 13.10 & 1.51 & 0.72 \\
$\mathrm{~T}-\mathrm{SOD}, \mathrm{U} / \mathrm{mL}$ & $190.10^{\mathrm{a}}$ & $207.44^{\mathrm{ab}}$ & $224.59^{\mathrm{b}}$ & 5.21 & 0.02 \\
$\mathrm{MDA}, \mathrm{nmol} / \mathrm{mL}$ & 2.33 & 1.74 & 1.59 & 0.14 & 0.07 \\
T-AOC, $\mathrm{mmol} / \mathrm{L}$ & 0.24 & 0.28 & 0.30 & 0.02 & 0.36 \\
GSH-P, U/mL & 634.15 & 670.15 & 664.61 & 12.54 & 0.48
\end{tabular}

${ }^{*}$ Experimental diets were control diet (CON), CON $+75 \mathrm{mg} / \mathrm{kg}$ aureomycin (ANT), CON $+1 \times 10^{8}$ CFU/kg S. boulardii mafic-1701 (SB). Blood was collected from one piglet selected from each replicate. In the same row, values with different lowercase letter superscripts mean significant difference $(P<0.05)$
Table 5 Effect of S. boulardii mafic-1701 on inflammatory parameters in jejunum and ileum in weaned piglets ${ }^{*}$

\begin{tabular}{llllll}
\hline Items & CON & ANT & SB & SEM & $P$-value \\
\hline $\begin{array}{l}\text { TNF-a, ng/L } \\
\text { Jejunum }\end{array}$ & $200.18^{\mathrm{a}}$ & $112.57^{\mathrm{b}}$ & $117.33^{\mathrm{b}}$ & 16.60 & $<0.01$ \\
Ileum & 101.59 & 123.24 & 157.42 & 13.38 & 0.31 \\
IL-8, ng/L & & & & & \\
$\quad$ Jejunum & 133.06 & 108.04 & 128.97 & 5.36 & 0.07 \\
$\quad$ Ieum & 286.76 & 160.73 & 177.90 & 25.12 & 0.06 \\
IL-6, ng/L & & & & & \\
Jejunum & $263.60^{\mathrm{a}}$ & $143.04^{\mathrm{b}}$ & $92.64^{\mathrm{b}}$ & 28.25 & $<0.01$ \\
Ileum & 111.61 & 111.66 & 132.87 & 8.25 & 0.60 \\
IL-4, ng/L & & & & & \\
Jejunum & 88.74 & 101.35 & 125.38 & 7.74 & 0.14 \\
Ileum & 87.31 & 99.18 & 105.40 & 3.64 & 0.06 \\
\hline
\end{tabular}

"Experimental diets were control diet (CON), CON $+75 \mathrm{mg} / \mathrm{kg}$ aureomycin (ANT), CON $+1 \times 10^{8} \mathrm{CFU} / \mathrm{kg}$ S. boulardii mafic-1701 (SB). Intestinal tissues were collected from three piglets per treatment. In the same row, values with different lowercase letter superscripts mean significant difference $(P<0.05)$

Figure 2 also shows that Firmicutes and Proteobacteria were the dominant phyla in the colonic digesta.

Principal component analysis (PCA) based on BrayCurtis distances indicated that SB group was distinctly separated in comparison to CON group and ANT group in the cecal microbiota (Fig. 3). Whereas, the colonic digesta of SB group were clustered with ANT group, which indicated that the colonic microbiota composition of ANT group and SB group was more similar.

Differences in the relative abundance of microbiota in the cecal and colonic digesta among three treatment groups are shown in cladograms, and the linear discriminant analysis (LDA) scores of 2.0 or higher were confirmed by the linear discriminant analysis effect size (LEfSe). In the cecal digesta (Fig. 4), the abundance of Bacillaceae family and Bacillales order were significantly increased in SB group $(P<0.05)$. Moreover, Ruminococcaceae_UCG_009 and Turicibacter genus were enriched in SB group $(P<0.05)$. In the colonic digesta (Fig. 5$)$, the proportion of Bacillus genus was significantly increased in SB group $(P<0.05)$, while greater relative abundance of Lactobacillales order and Prevotella_1 genus were observed in CON group $(P<0.05)$ In addition, the abundance of unclassified_Clostridiaceae_4 genus and its family Clostridiaceae_4 were significantly enriched in ANT group $(P<0.05)$.

\section{Concentrations of fermentation metabolites}

SCFAs in the cecal and colonic digesta are presented in Table 6. The results showed that SB group had higher concentrations of isobutyrate and valerate in the cecal digesta than piglets in CON group $(P<0.05)$. 


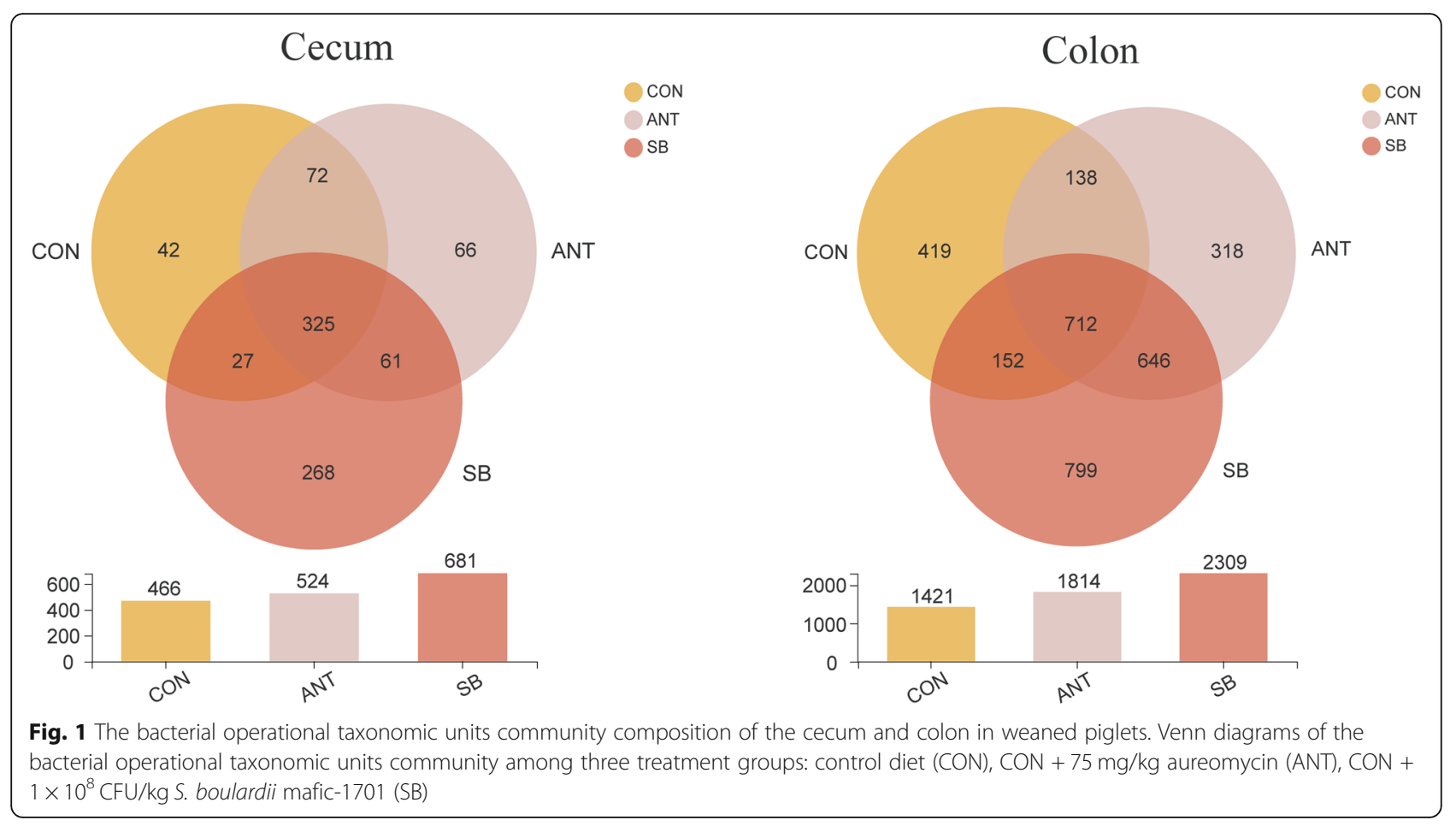

\section{Discussion}

S. boulardii is an important species of microorganism, which has known positive effects on gut health of human $[11,12]$. Unfortunately, data on the effect of S. boulardii on weaned piglets are limited. Therefore, in this study we investigated the effects of $S$. boulardii mafic1701 supplemented in the diet on weaned piglet health and gut microbiota composition over 4 weeks. The dose of $S$. boulardii mafic-1701 was selected according to the studies by Kamm et al. [21] and Hancox et al. [22] The two doses of $S$. boulardii in their studies were $1 \times 10^{7}$ $\mathrm{CFU} / \mathrm{kg}$ and $1 \times 10^{9} \mathrm{CFU} / \mathrm{kg}$, respectively. We selected $1 \times 10^{8} \mathrm{CFU} / \mathrm{kg}$, the middle dose of $S$. boulardii of the two studies as the experimental treatment in this study.

In the present study, supplementation of $S$. boulardii mafic-1701 improved feed conversion ratio compared with $\mathrm{CON}$ group. A previous study reported that administration of yeast improved feed conversion ratio of weaned piglets [23], which is in agreement with our results. Reports on the effect of dietary

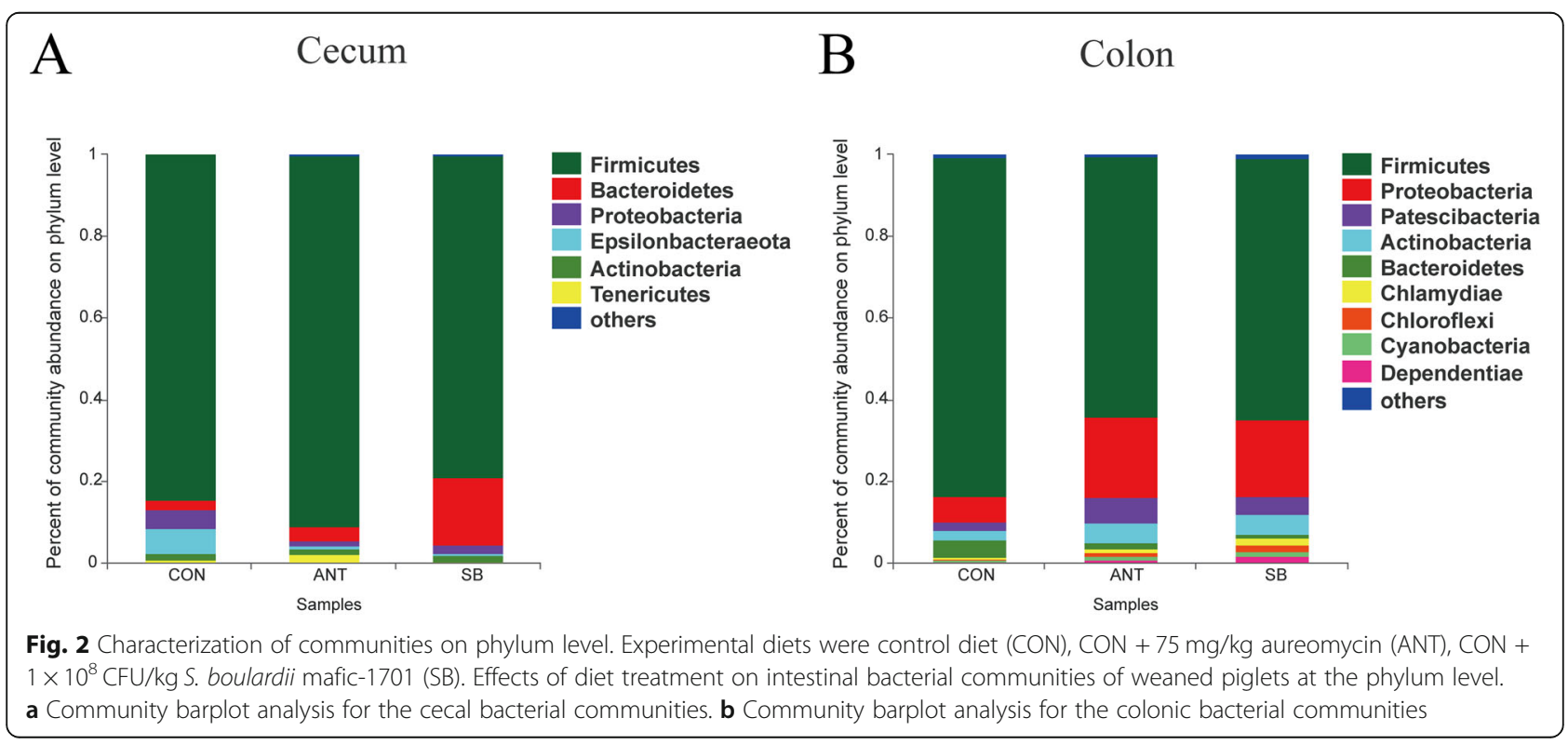




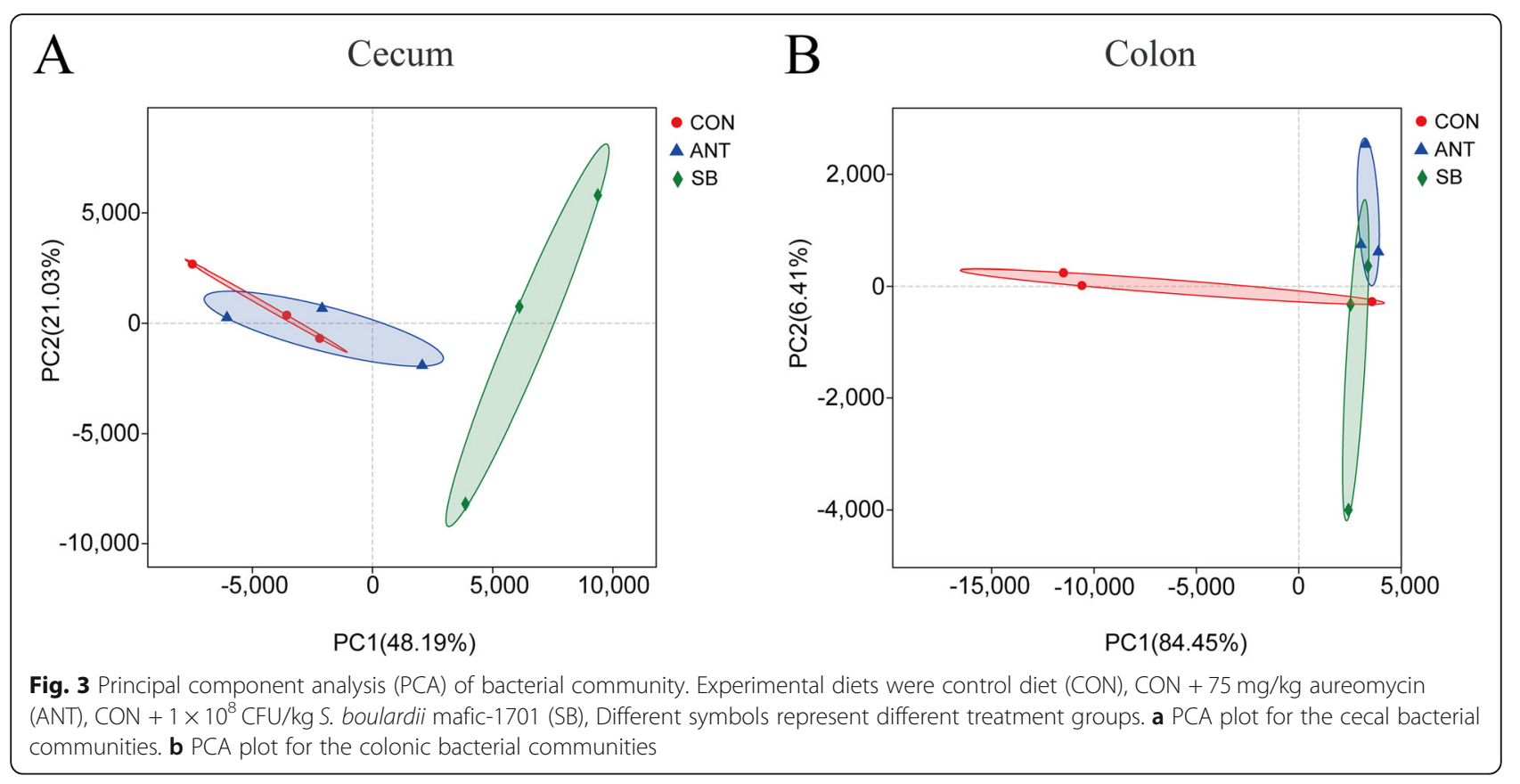

supplementation of $S$. boulardii on the rate of diarrhea of weaned piglets are limited. The current study demonstrated that the dietary supplementation of $S$. boulardii mafic-1701 significantly decreased the rate of diarrhea over the entire 4 weeks.

It is generally known that weaning could lead to breakdown of intestinal barrier functions [24, 25]. When the intestinal barrier is damaged, microbial colonization increases the risk of inflammation [26]. In this study, we found that the levels of pro-inflammatory cytokines
TNF- $\alpha$ and IL- 6 were decreased in SB group compared with $\mathrm{CON}$ group, but there were no significant differences on the levels of IL- 8 and IL- 4 among three treatment groups. A previous study also reported that $S$. boulardii could reduce TNF- $\alpha$ and IL- 6 levels in mice ulcerative colitis carcinogenesis model [27]. These results indicated that $S$. boulardii mafic-1701 has beneficial effects on intestinal health by decreasing inflammation. Previous studies showed that $S$. boulardii blocked nuclear factor kappa B activation and reduced

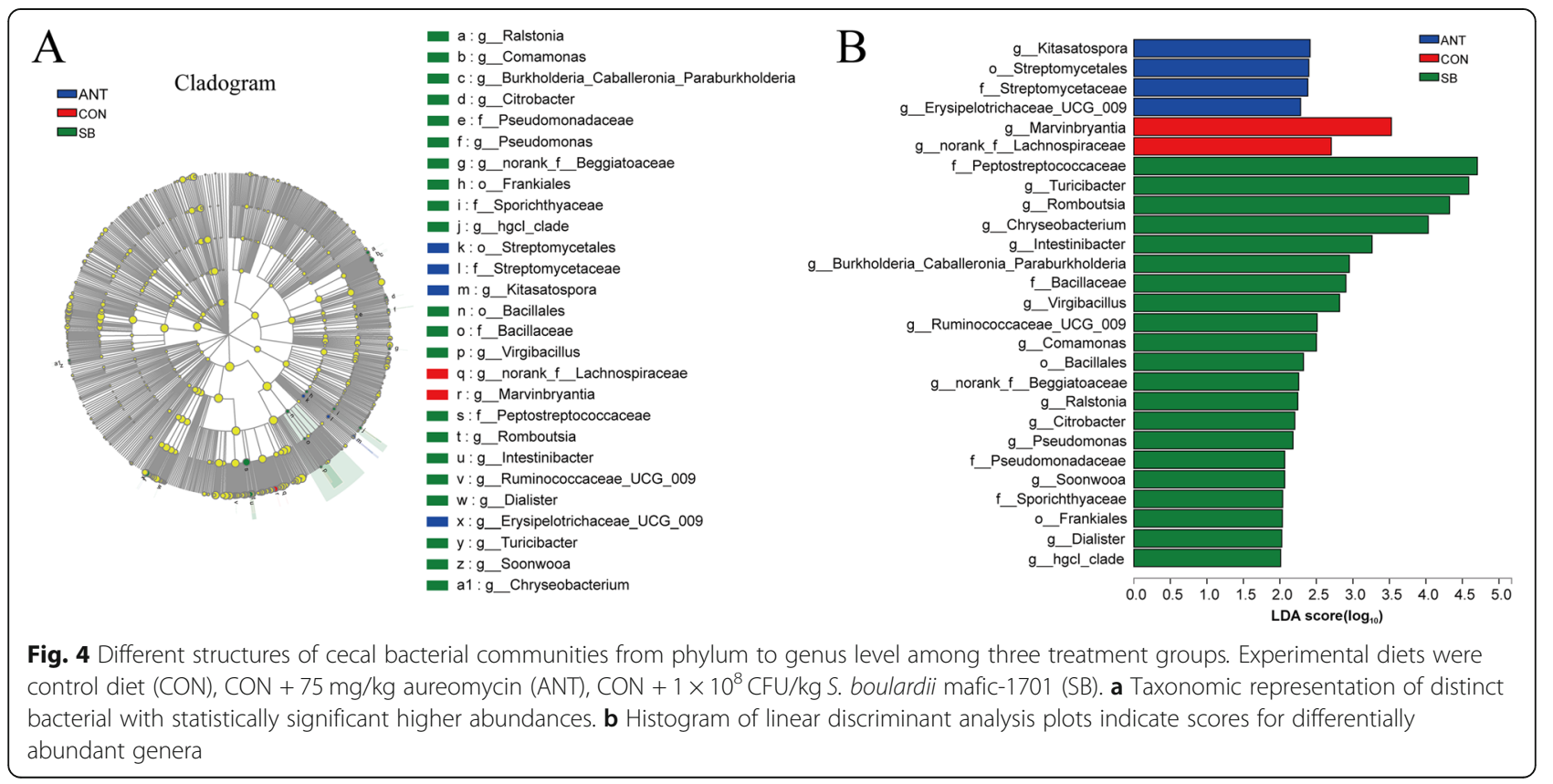




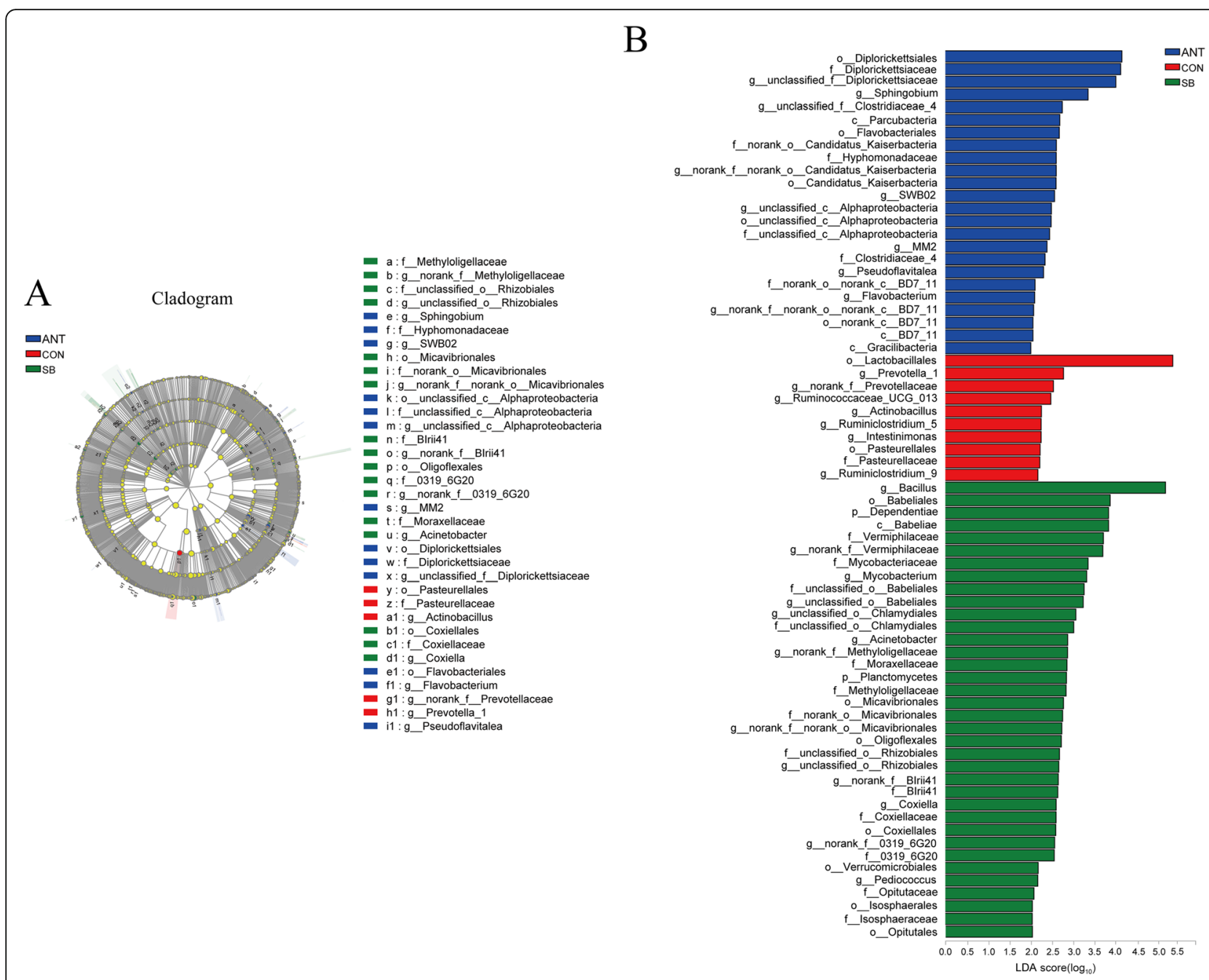

Fig. 5 Different structures of colonic bacterial communities from phylum to genus level among three treatment groups. Experimental diets were control diet (CON), CON $+75 \mathrm{mg} / \mathrm{kg}$ aureomycin (ANT), CON $+1 \times 10^{8} \mathrm{CFU} / \mathrm{kg}$ S. boulardii mafic-1701 (SB). a Taxonomic representation of distinct bacterial with statistically significant higher abundances. $\mathbf{b}$ Histogram of linear discriminant analysis plots indicate scores for differentially abundant genera

colonic inflammation $[28,29]$. Thus, we speculate that $S$. boulardii mafic-1701 altered the levels of proinflammatory cytokines through modulation of the signaling pathway involved in the inhibition of nuclear factor kappa B activated pathways. In addition, other previous studies have reported that mucus is composed of many immunomodulatory molecules with mucins forming the basic skeleton, which protect intestinal epithelial barrier integrity and reduce pro-inflammatory responses [4, 30]. Caballero-Franco et al. demonstrated that oral administration of probiotic increased mucin gene expression and secretion [31]. Therefore, it is speculated that S. boulardii mafic-1701 has a modulatory effect on inflammatory responses that correlates with the regulation of mucin transcription.

Probiotics can activate the local mucosal protective mechanisms and exert beneficial effects on the host such as modulate anti-oxidation and immune responses [32, 33]. In our study, we observed that $S$. boulardii mafic1701 and aureomycin supplementation had no effect on IgA and IgG levels in the serum. In terms of antioxidant analysis, we found that T-SOD was increased in the SB group of the piglets, which suggests $S$. boulardii mafic1701 plays a role in improving antioxidant capacity and protecting intestinal mucosa [33].

The diversity of the microorganisms in the mammalian gut is very large. It has been estimated that 500 1000 bacterial species inhabit the gut [34]. The gut microbiota has a symbiotic relationship with the host. Oral ingestion of a feed additive can regulate the delicate balance between host and microbes. From the results of phylum analysis, we found that the cecum microbial floras were dominated by Firmicutes, which is consistent with previous findings reported by $\mathrm{Yu}$ et al. [35]. Wang 
Table 6 Effect of S. boulardii mafic-1701 on the concentrations of SCFAs $(\mathrm{mg} / \mathrm{kg})$ in weaned piglets ${ }^{*}$

\begin{tabular}{|c|c|c|c|c|c|}
\hline Items & CON & ANT & SB & SEM & $P$-value \\
\hline \multicolumn{6}{|l|}{ Acetate } \\
\hline Cecum & 3724.49 & 4052.51 & 3494.39 & 112.17 & 0.13 \\
\hline Colon & 4102.98 & 4527.22 & 4245.64 & 74.78 & 0.05 \\
\hline \multicolumn{6}{|l|}{ Propionate } \\
\hline Cecum & 2241.26 & 2484.82 & 2812.71 & 221.88 & 0.60 \\
\hline Colon & $2686.08^{a}$ & $3252.93^{b}$ & $2861.84^{a}$ & 81.83 & $<0.01$ \\
\hline \multicolumn{6}{|l|}{ Formate } \\
\hline Cecum & 36.77 & 62.54 & 72.37 & 6.43 & 0.06 \\
\hline Colon & 58.27 & 63.13 & 68.00 & 4.20 & 0.67 \\
\hline \multicolumn{6}{|l|}{ Isobutyrate } \\
\hline Cecum & $2.89^{a}$ & $5.10^{\mathrm{ab}}$ & $15.60^{b}$ & 2.42 & 0.03 \\
\hline Colon & 42.35 & 44.60 & 28.09 & 3.26 & 0.05 \\
\hline \multicolumn{6}{|l|}{ Butyrate } \\
\hline Cecum & 870.88 & 1114.59 & 1204.74 & 87.96 & 0.29 \\
\hline Colon & $1499.63^{a}$ & $2105.30^{b}$ & $1833.76^{\mathrm{ab}}$ & 97.96 & 0.03 \\
\hline \multicolumn{6}{|l|}{ Isovalerate } \\
\hline Cecum & $2.15^{\mathrm{a}}$ & $11.67^{b}$ & $5.47^{a b}$ & 1.64 & 0.04 \\
\hline Colon & 36.80 & 36.70 & 22.72 & 4.55 & 0.35 \\
\hline \multicolumn{6}{|l|}{ Valerate } \\
\hline Cecum & $92.16^{a}$ & $211.31^{b}$ & $235.98^{b}$ & 24.69 & 0.01 \\
\hline Colon & $250.90^{\mathrm{a}}$ & $460.89^{b}$ & $258.83^{\mathrm{a}}$ & 35.87 & 0.01 \\
\hline
\end{tabular}

"Experimental diets were control diet (CON), $\mathrm{CON}+75 \mathrm{mg} / \mathrm{kg}$ aureomycin (ANT), CON $+1 \times 10^{8} \mathrm{CFU} / \mathrm{kg}$ S. boulardii mafic-1701 (SB). Cecal and colonic digesta were collected from three piglets per treatment and the concentrations of SCFAs were measured. In the same row, values with different lowercase letter superscripts mean significant difference $(P<0.05)$

et al. reported a significant increase in abundance of Firmicutes and decrease in abundance of Bacteroidetes in which piglets were fed probiotics [14]. In the present study, compared to CON group, we found an increased abundance of Proteobacteria and decreased abundance of Firmicutes and Bacteroidetes in the colon in SB group. Difference between the Wang et al. study and this study may be attributed to the use of different probiotic strains. Indeed, different probiotic strains could exert different physiological effects.

From current study, S. boulardii mafic-1701 inclusion resulted in higher bacterial diversity in cecum and colon of piglets. The population of Ruminococcaceae_UCG 099 and Turicibacter genus were significantly increased in cecum of SB group compared to CON group. These bacteria are believed to be significant producers of SCFAs, which are intestinal epithelial energy components that have anti-inflammatory properties and protect intestinal epithelial cells [36-38]. In addition, Ruminococcaceae can utilize diverse polysaccharides [39]. Indeed, the yeast cell wall consists of mannose, chitin, 1,3$\beta$-glucan and 1,6- $\beta$-glucan [6]. Therefore, the increased population of Ruminococcaceae_UCG_099 in the cecum might be due to $S$. boulardii mafic-1701 being used as a substrate source to stimulate proliferation of Ruminococcaceae_UCG_099. S. boulardii mafic-1701 inclusion showed some alterations with regard to microbiota communities. In the colon, S. boulardii mafic-1701 inclusion increased the abundance of Bacillus genus, which have excellent immunomodulatory and anti-inflammatory efficacy [40, 41]. In addition, a previous study reported that several Bacillus species, reduced pathogen colonization but the mechanisms by which this occurs is unclear [42]. Notably, the relative abundance of Clostridiaceae_4 family, which are negatively linked with antibiotic-associated diarrhea and colitis, was significantly increased in ANT group compared with SB group. It has been demonstrated that antibiotic treatment alters the composition of gut microbiota, manifesting the host susceptible to pathogen infection $[24,43]$.

Microbially-produced SCFAs as crucial in regulating health of the host and play a central role in gut metabolism [44]. A previously published report indicated that probiotics can increase SCFAs production [14]. In this study, S. boulardii mafic-1701 supplementation increased the concentrations of cecal isobutyrate and valerate. Compared with the other two groups, ANT group increased the concentrations of colonic propionate and butyrate. The increase of SCFAs production may be associated with the types of food where the fed intake is the most significant variable [45].

\section{Conclusion}

In conclusion, dietary supplementation of $S$. boulardii mafic-1701 improved F:G, decreased the rate of diarrhea, increased the serum concentration of T-SOD, and decreased the levels of TNF- $\alpha$, IL- 6 in jejunum of weaned piglets. In addition, diets supplemented with $S$. boulardii mafic-1701 enriched the abundance of Ruminococcaceae_UCG_099, Turicibacter in the cecal digesta, which may contribute to the higher concentrations of cecal SCFAs. These findings suggest that supplementation of S. boulardii mafic-1701 in diets improved feed conversion ratio and antioxidant capacity, alleviated diarrhea and inflammation, and regulated gut health by promoting beneficial bacteria and their fermentation metabolites in weaned piglets.

\footnotetext{
Abbreviations

S. boulardii: Saccharomyces boulardii; ADG: Average daily gain; ADFI: Average daily feed intake; F:G: Feed to gain ratio; SCFAs: Short chain fatty acids; TSOD: Total superoxide dismutase; MDA: Malondialdehyde; T-AOC: Total antioxidant capacity; GSH-Px: Glutathione peroxidase; IL-8: Interleukin-8; IL4: Interleukin-4; IL-6: Interleukin-6; TNF-a: Tumor necrosis factor-a; OTUs: Operational taxonomic units; PCA: Principal component analysis; LDA: Linear discriminant analysis; LEfSe: Linear discriminant analysis effect size
} 


\section{Acknowledgements}

The authors would like to express special appreciate to Dr. Crystal Levesque, the professor of Department of Animal Science, South Dakota State University for providing many insight comments and correcting the language.

\section{Authors' contributions}

WXZ and YHC designed the experiment. WXZ, CLB and JW performed the experiment. JJZ supervised the whole experiment. WXZ wrote the paper, YHC edited the paper. All authors read and approved the final manuscript.

\section{Funding}

This work was supported by National Key R\&D Program of China (No.2018YDF0500604) and the Key Research \& Development Program of Shandong Province (2019JZZY020308).

\section{Availability of data and materials}

The data analyzed during the current study are available from the corresponding author on reasonable request.

\section{Ethics approval and consent to participate}

This study was approved by Committee of China Agricultural University Laboratory Animal Care and Use (Beijing, China).

\section{Consent for publication}

Not applicable.

\section{Competing interests}

The authors declare that they have no competing interests.

Received: 1 April 2020 Accepted: 8 October 2020

Published online: 04 December 2020

\section{References}

1. Hu J, Ma L, Nie Y, Chen J, Zheng W, Wang X, et al. A microbiota-derived bacteriocin targets the host to confer diarrhea resistance in early-weaned piglets. Cell Host Microbe. 2018:24:817-32.

2. Gresse R, Chaucheyras-Durand F, Fleury MA, Van de Wiele T, Forano E, Blanquet-Diot S. Gut microbiota dysbiosis in postweaning piglets: understanding the keys to health. Trends Microbiol. 2017;25:851-73.

3. Wang T, Teng K, Liu Y, Shi W, Zhang J, Dong E, et al. Lactobacillus plantarum PFM 105 promotes intestinal development through modulation of gut microbiota in weaning piglets. Front Microbiol. 2019;10:90.

4. $\quad Y u$ H, Wang $Y$, Zeng $X$, Cai S, Wang G, Liu L, et al. Therapeutic administration of the recombinant antimicrobial peptide microcin $J 25$ effectively enhances host defenses against gut inflammation and epithelial barrier injury induced by enterotoxigenic Escherichia coli infection. FASEB J. 2019:34:1018-37.

5. Hill C, Guarner F, Reid G, Gibson GR, Merenstein DJ, Pot B, et al. The international scientific association for probiotics and prebiotics consensus statement on the scope and appropriate use of the term probiotic. Nat Rev Gastroenterol Hepatol. 2014;11:506-14.

6. Czerucka D, Piche T, Rampal P. Review article: yeast as probiotics -Saccharomyces boulardii. Aliment Pharmacol Ther. 2007;26:767-78.

7. Lazo-Velez MA, Serna-Saldivar SO, Rosales-Medina MF, Tinoco-Alvear M, Briones-Garcia M. Application of Saccharomyces cerevisiae var. boulardii in food processing: a review. J Appl Microbiol. 2018;125:943-51.

8. Fratianni F, Cardinale F, Russo I, Iuliano C, Tremonte P, Coppola R, et al. Ability of synbiotic encapsulated Saccharomyces cerevisiae boulardii to grow in berry juice and to survive under simulated gastrointestinal conditions. J Microencapsul. 2014;31:299-305.

9. Castagliuolo I, Riegler MF, Valenick L, LaMont JT, Pothoulakis C. Saccharomyces boulardii protease inhibits Clostridium difficile toxin a effects in the rat ileum. Infect Immun. 1996;64:5225-32.

10. Koon HW, Su B, Xu C, Mussatto CC, Tran DH, Lee EC, et al. Probiotic Saccharomyces boulardii CNCM I-745 prevents outbreak-associated Clostridium difficile-associated cecal inflammation in hamsters. Am J Physio Gastrointest Liver Physiol. 2016:311:G610-23.

11. Kabbani TA, Pallav K, Dowd SE, Villafuerte-Galvez J, Vanga RR, Castillo NE, et al. Prospective randomized controlled study on the effects of Saccharomyces boulardii CNCM I-745 and amoxicillin-clavulanate or the combination on the gut microbiota of healthy volunteers. Gut Microbes. 2017:8:17-32.

12. McFarland LV. Meta-analysis of probiotics for the prevention of antibiotic associated diarrhea and the treatment of Clostridium difficile disease. Am J Gastroenterol. 2006;101:812-22.

13. Wang J, Liu Y, Yang Y, Bao C, Cao Y. High-level expression of an acidic thermostable xylanase in Pichia pastoris and its application in weaned piglets. J Anim Sci. 2020;98:1

14. Wang S, Yao B, Gao H, Zang J, Tao S, Zhang S, et al. Combined supplementation of Lactobacillus fermentum and Pediococcus acidilactici promoted growth performance, alleviated inflammation, and modulated intestinal microbiota in weaned pigs. BMC Vet Res. 2019;15:239.

15. Hart GK, Dobb GJ. Effect of a fecal bulking agent on diarrhea during enteral feeding in the critically ill. Jpen-Parenter Enter. 1988;12:465.

16. Pan L, Zhao PF, Ma XK, Shang OH, Xu YT, Long SF, et al. Probiotic supplementation protects weaned pigs against enterotoxigenic Escherichia coli K88 challenge and improves performance similar to antibiotics. J Anim Sci. 2017;95:2627-39

17. Sun YB, Xia $T$, Wu H, Zhang WJ, Zhu YH, Xue JX, et al. Effects of nano zinc oxide as an alternative to pharmacological dose of zinc oxide on growth performance, diarrhea, immune responses, and intestinal microflora profile in weaned piglets. Anim Feed Sci Tech. 2019;258:114312.

18. Liu P, Zhao J, Wang W, Guo P, Lu W, Wang C, et al. Dietary corn bran altered the diversity of microbial communities and cytokine production in weaned pigs. Front Microbiol. 2018;9:2090.

19. Aluko K, Velayudhan DE, Khafipour E, Li A, Yin Y, Nyachoti M. Combined effects of chitosan and microencapsulated Enterococcus faecalis CG1.0007 probiotic supplementation on performance and diarrhea incidences in enterotoxigenic Escherichia coli K88+ challenged piglets. Anim Nutr. 2017;3: $366-71$

20. Bailey NTJ. Statistical methods in biology. 2rd ed. New York: Cambridge University Press; 1981

21. Kamm K, Hoppe S, Breves G, Schroder B, Schemann M. Effects of the probiotic yeast Saccharomyces boulardii on the neurochemistry of myenteric neurones in pig jejunum. Neuroga Stroent Motil. 2004;16:53-60.

22. Hancox LR, Le Bon M, Richards PJ, Guillou D, Dodd CE, Mellits KH. Effect of a single dose of Saccharomyces cerevisiae var. boulardii on the occurrence of porcine neonatal diarrhoea. Animal. 2015:9:1756-9.

23. Jiang Z, Wei S, Wang Z, Zhu C, Hu S, Zheng C, et al. Effects of different forms of yeast Saccharomyces cerevisiae on growth performance, intestinal development, and systemic immunity in early-weaned piglets. J Anim Sci Biotechnol. 2015;6:47.

24. Wang J, Ji H, Wang S, Liu H, Zhang W, Zhang D, et al. Probiotic Lactobacillus plantarum promotes intestinal barrier function by strengthening the epithelium and modulating gut microbiota. Front Microbiol. 2018;9:1953.

25. Spreeuwenberg MA, Verdonk JM, Gaskins HR, Verstegen MWA. Small intestine epithelial barrier function is compromised in pigs with low feed intake at weaning. J Nutr. 2001;131:1520.

26. Peterson LW, Artis D. Intestinal epithelial cells: regulators of barrier function and immune homeostasis. Nat Rev Immunol. 2014;14:141-53.

27. Wang C, Li W, Wang H, Ma Y, Zhao X, Zhang X, et al. Saccharomyces boulardii alleviates ulcerative colitis carcinogenesis in mice by reducing TNF-alpha and IL-6 levels and functions and by rebalancing intestinal microbiota. BMC Microbiol. 2019;19:246.

28. Sougioultzis S, Simeonidis S, Bhaskar KR, Chen X, Anton PM, Keates S, et al. Saccharomyces boulardii produces a soluble anti-inflammatory factor that inhibits NF-kappaB-mediated IL-8 gene expression. Biochem Biophys Res Commun. 2006;343:69-76.

29. Lee SK, Kim YW, Chi SG, Joo YS, Kim HJ. The effect of Saccharomyces boulardii on human colon cells and inflammation in rats with trinitrobenzene sulfonic acid-induced colitis. Dig Dis Sci. 2009:54:255-63.

30. Johansson ME, Hansson GC. Immunological aspects of intestinal mucus and mucins. Nat Rev Immunol. 2016;16:639-49.

31. Caballero-Franco C, Keller K, De Simone C, Chadee K. The VSL\#3 probiotic formula induces mucin gene expression and secretion in colonic epithelial cells. Am J Physiol Gastrointest Liver Physiol. 2007:292:G315-22.

32. Gobi N, Vaseeharan B, Chen JC, Rekha R, Vijayakumar S, Anjugam M, et al. Dietary supplementation of probiotic Bacillus licheniformis Dahb1 improves growth performance, mucus and serum immune parameters, antioxidant enzyme activity as well as resistance against Aeromonas hydrophila in tilapia Oreochromis mossambicus. Fish Shellfish Immunol. 2018;74:501-8. 
33. Rajput IR, Li YL, Xu X, Huang Y, Zhi WC, Yu DY, et al. Supplementary effects of Saccharomyces boulardii and Bacillus subtilis B10 on digestive enzyme activities, antioxidation capacity and blood homeostasis in broiler. Int J Agric Biol. 2013:15:231-7.

34. Kim HB, Isaacson RE. The pig gut microbial diversity: understanding the pig gut microbial ecology through the next generation high throughput sequencing. Vet Microbiol. 2015;177:242-51.

35. Yu L, Zhao XK, Cheng ML, Yang GZ, Wang B, Liu HJ, et al. Saccharomyces boulardii administration changes gut microbiota and attenuates Dgalactosamine-induced liver injury. Sci Rep. 2017;7:1359.

36. Suchodolski JS, Markel ME, Garcia-Mazcorro JF, Unterer S, Heilmann RM, Dowd SE, et al. The fecal microbiome in dogs with acute diarrhea and idiopathic inflammatory bowel disease. PLoS One. 2012;7:e51907.

37. Lo Presti A, Zorzi F, Del Chierico F, Altomare A, Cocca S, Avola A, et al. Fecal and mucosal microbiota profiling in irritable bowel syndrome and inflammatory bowel disease. Front Microbiol. 2019;10:1655.

38. Rossi G, Pengo G, Caldin M, Palumbo Piccionello A, Steiner JM, Cohen ND, et al. Comparison of microbiological, histological, and immunomodulatory parameters in response to treatment with either combination therapy with prednisone and metronidazole or probiotic VSL\#3 strains in dogs with idiopathic inflammatory bowel disease. PLoS One. 2014;9:e94699.

39. Shang Q, Shan X, Cai C, Hao J, Li G, Yu G. Dietary fucoidan modulates the gut microbiota in mice by increasing the abundance of Lactobacillus and Ruminococcaceae. Food Funct. 2016;7:3224-32.

40. Shinde T, Perera AP, Vemuri R, Gondalia SV, Beale DJ, Karpe AV, et al. Synbiotic supplementation with prebiotic green banana resistant starch and probiotic Bacillus coagulans spores ameliorates gut inflammation in mouse model of inflammatory bowel diseases. Eur J Nutr. 2020. https://doi.org/10. 1007/s00394020022009.

41. Rhayat L, Maresca M, Nicoletti C, Perrier J, Brinch KS, Christian S, et al. Effect of Bacillus subtilis strains on intestinal barrier function and inflammatory response. Front Immunol. 2019;10:564.

42. Piewngam P, Zheng Y, Nguyen TH, Dickey SW, Joo HS, Villaruz AE, et al. Pathogen elimination by probiotic Bacillus via signalling interference. Nature. 2018;562:532-7.

43. Round JL, Mazmanian SK. The gut microbiota shapes intestinal immune responses during health and disease. Nat Rev Immunol. 2009;9:313.

44. Cho I, Yamanishi S, Cox L, Methe BA, Zavadil J, Li K, et al. Antibiotics in early life alter the murine colonic microbiome and adiposity. Nature. 2012;488.

45. Wong JMW, De Souza R, Kendall CWC, Emam A, Jenkins DJA. Colonic health: fermentation and short chain fatty acids. J Clin Gastroenterol. 2006; 40:235-43.

Ready to submit your research? Choose BMC and benefit from:

- fast, convenient online submission

- thorough peer review by experienced researchers in your field

- rapid publication on acceptance

- support for research data, including large and complex data types

- gold Open Access which fosters wider collaboration and increased citations

- maximum visibility for your research: over $100 \mathrm{M}$ website views per year

At $\mathrm{BMC}$, research is always in progress.

Learn more biomedcentral.com/submissions 